\title{
neuroRAD geht in zweite Frankfurt/Main-Runde
}

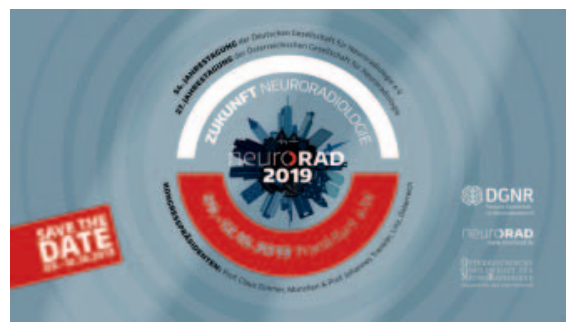

Nach dem Frankfurter Auftakt im Jahr 2018 laden die Deutsche Gesellschaft für Neuroradiologie und die Österreichische Gesellschaft für Neuroradiologie zu ihrer 54. Jahrestagung wieder an den Main ein, genauer: vom 9. bis 12. Oktober 2019 in das Kongresscenter Kap Europa.

Die Neuroradiologie als DAS Querschnittsfach für die Medizin der Zukunft herauszustellen und den Einfluss durch das Feld Künstliche Intelligenz auszuloten: Diese Leitmotive stehen unter dem Kongressmotto des neuroRAD 2019 „Zukunft Neuroradiologie“.
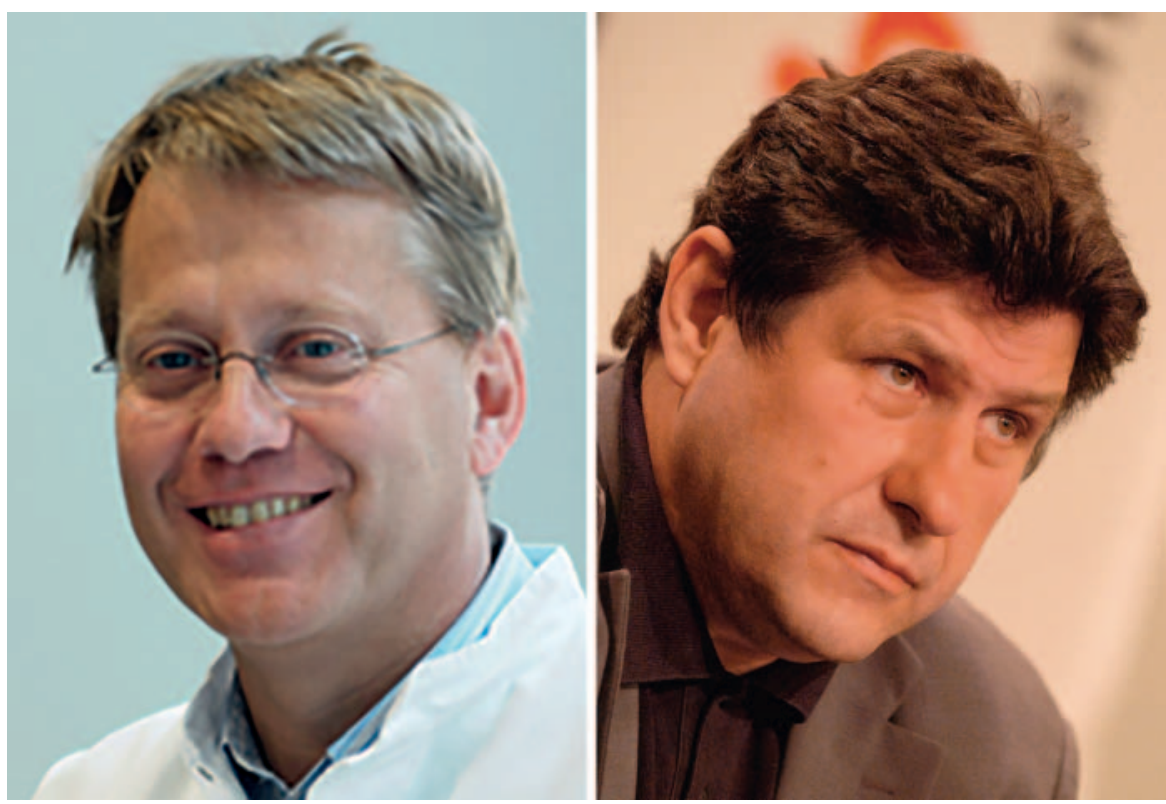

Die Kongresspräsidenten des 54. neuroRAD 2019: Prof. Claus Zimmer (München) und Prof. Johannes Trenkler (Linz). 
Im Mittelpunkt des Kongresses stehen nicht nur die Fit-für-den-Facharzt-Kurse, VideoCases, Keynote-Lectures, der Neuro-Anatomie-Kurs und das MTRA-Programm, sondern auch die in 2018 gestartete German Stroke School sowie ein neues Forum, die StARLounge (Start-up and Applied Research), die Entwickler von Künstlicher Intelligenz, Robotic und Big-Data-Analysen mit Anwendern zusammenbringt. Neu insbesondere für den wissenschaftlichen Nachwuchs ist ein Format, bei dem Referenten in Sessions ihr Projekt in stark begrenzter Zeit auf den Punkt bringen müssen, bevor es zur Diskussion am Poster kommt.

Wir freuen uns auf Ihre Teilnahme am neuroRAD 2019 in Frankfurt am Main!
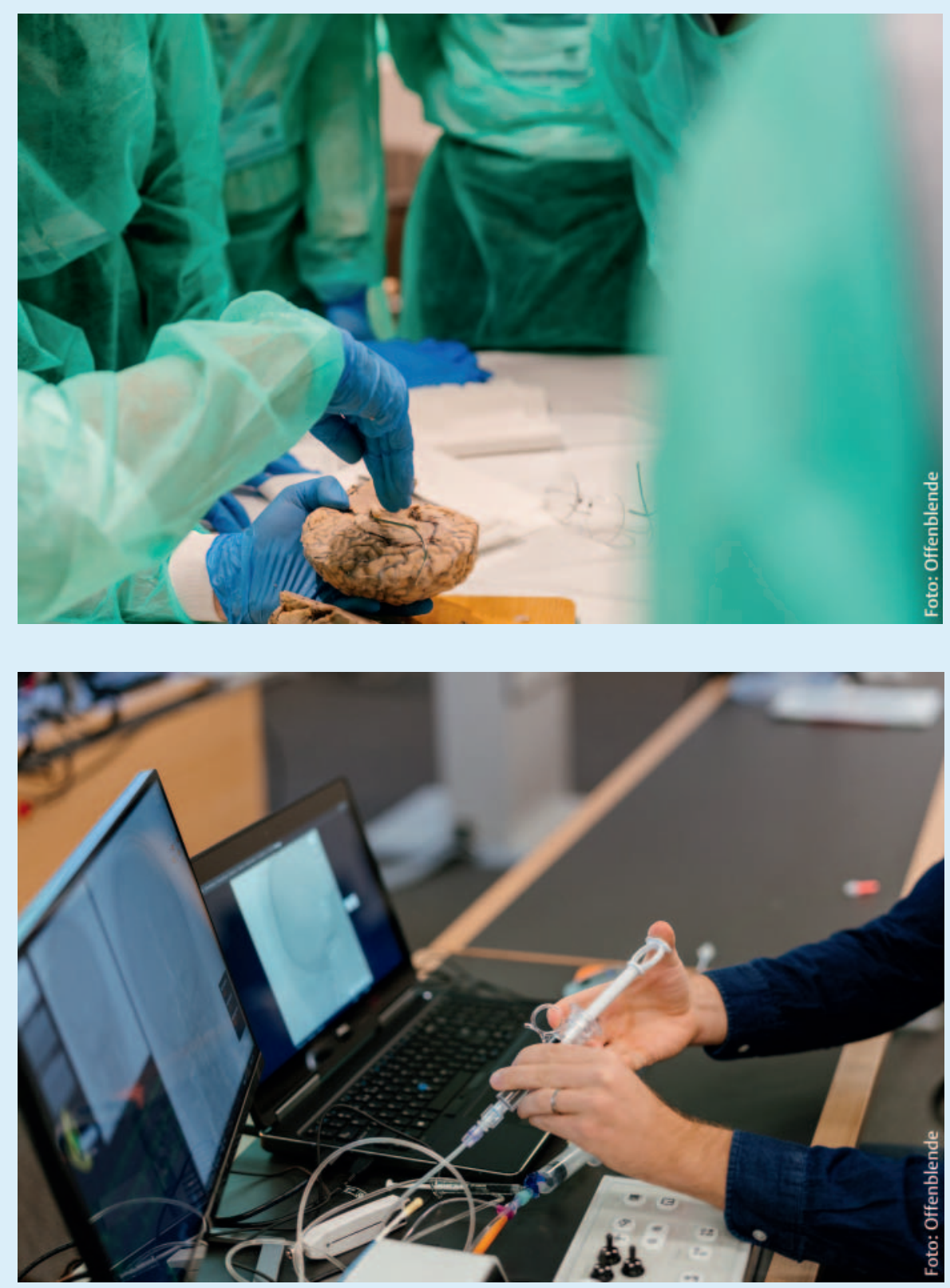